\title{
The slope seismic response monitoring of Wenchuan aftershocks in Qingchuan
}

\section{Y. H. Luo, R. Huang, and Y. Wang}

State Key Laboratory of Geohazard Prevention and Geoenvironment Protection, Chengdu University of Technology, Chengdu 610059, China

Received: 16 February 2014 - Accepted: 6 April 2014 - Published: 6 June 2014

Correspondence to: Y. H. Luo (luoyonghong2012@cdut.cn)

Published by Copernicus Publications on behalf of the European Geosciences Union.

The slope seismic response monitoring of Wenchuan

Y. H. Luo et al.

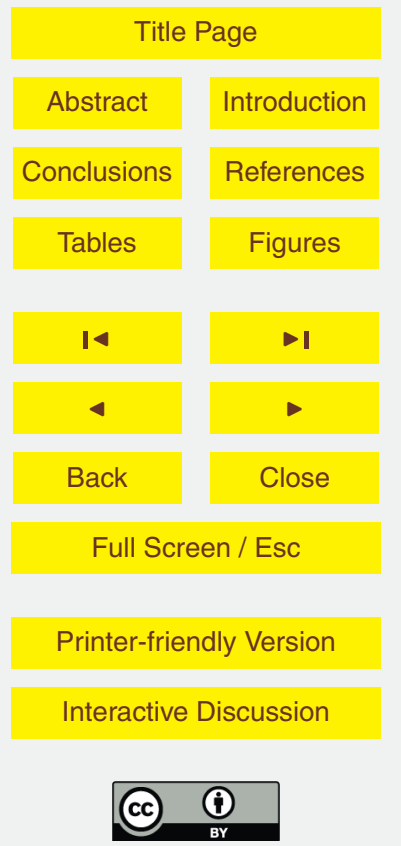




\section{Abstract}

This work reports some new progress of rock slope inside seismic response monitoring results in the area of Mountain Dong and Mountain Shizi (Qingchuan county), located more than $250 \mathrm{~km}$ NE of Yingxiu epicenter (2008 Wenchuan earthquake), Sichuan 5 province. Five adits with the maximum depth of $15 \mathrm{~m}$ had been excavated in different elevation on both sides slope. Stations were emplaced at middle of the adits, from September 2009 to May 2010 more than 60 Wenchuan aftershocks had been monitored, 22 typical aftershocks had been analysis, whose magnitude varied between $2.3 \sim 5.2$ and epicentral distance was from a few to $45 \mathrm{~km}$. A comparison analysis of recordings provided evidence of the presence amplification effect at the Q4 station of Mt. Dong, which the peak horizontal acceleration amplification factor is between $1.0 \sim 2.5$. But this amplification effect had no stronger at other stations. Comprehensive studies show that the relative height to riverbed is an important factor of Q4 seismic amplification effect. Otherwise the topography of Q4 site is conducive to horizontal amplification, not the vertical amplification. Moreover the calculation of Arias intensity (la) had the same amplification effect as the PGA, only the amplification factor is between $1.0 \sim 3.47$ much bigger than the latter. On the other hand, the calculation of horizontal to vertical spectral ratio (HVSR) at Q4 shows the curves have multiple peaks corresponding with different dominant frequencies, which the amplification factor is always bigger than other stations at Mt. Dong. Sufficient evidence indicates that the Mt. Dong amplification effect is stronger than Mt. Shizi.

\section{Introduction}

Slope seismic amplification effect has always been an interesting scientific question due to the topography, lithology, structure and other factors of the slope are relationship to the ground vibration. Even though the Qingchuan county is far away from the epicenter of Wenchuan earthquake, strong seismic dynamic failure were also found
NHESSD

2, 4135-4161, 2014

The slope seismic response monitoring of Wenchuan

Y. H. Luo et al.

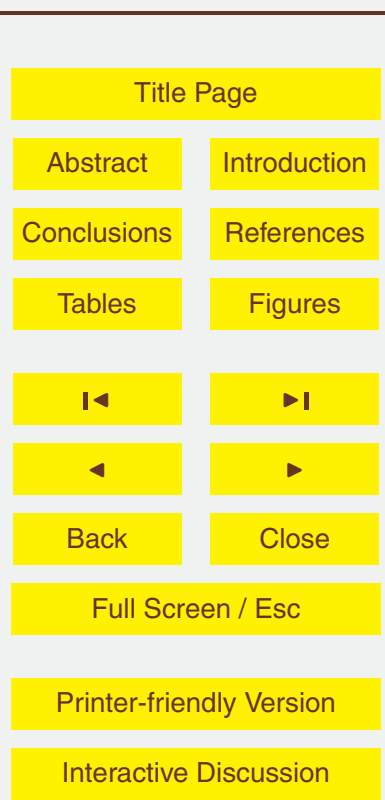


around the periphery county town such as the Mountain Dong (Mt. Dong), Mountain Shizi (Mt. Shizi) and Weigan hill (Fig. 1). Earthquake cracks and rock falls always were distribution along the ridges, while some rock falls or landslides were always distribution at a relative height to riverbed. Field experiments at the crest and base of Kagel 5 Mountain and Josephine Peak, California concluded that the topography plays a significant role and is an important consideration in determining the seismic motion (Davis and West, 1973). Many of the observed characteristics of seismic response at Tarzana are explained in part by its topography (Bouchon and Barker, 1996). A field program of topography on seismic-wave motions in the Appalachian was showing that the ra10 tios between mountaintop and the valley sites were amplified by factors from 1.7 to 3.4 (Griffiths and Bollinger, 1979). Other experimental studies and theoretical predictions have got amplifications of incident seismic signals by rock sites to be as large as the factor between $1.5 \sim 6.0$ (Bouchon, 1973; Wong and Jennings, 1975; Lee et al., 2008). In this paper, we report a systematic slope seismic dynamic response monitor15 ing on both sides of Qiaozhuang river, Qingchuan county. Five monitoring adits with each $15 \mathrm{~m}$ depth were excavated on the different elevations of Mt. Dong and Mt. Shizi and the stations were emplaced at the middle of the adit. From 2009 to 2010 those five monitoring stations recorded dozens of Wenchuan aftershocks, this study describes dozens of group typical aftershocks that were triggering more than three stations to analyze the horizontal and vertical components of peak ground acceleration (PGA), the arias intensity (la) and those synthesis values for the amplification effect along with the altitude at Mt. Dong and Mt. Shizi. In addition, the horizontal to vertical spectral ratios (HVSR) was calculation as a comparison analysis. Those results are analyzed to investigate the variations of amplification relationship with relative height to riverbed,
NHESSD

2, 4135-4161, 2014

The slope seismic response monitoring of Wenchuan

Y. H. Luo et al.

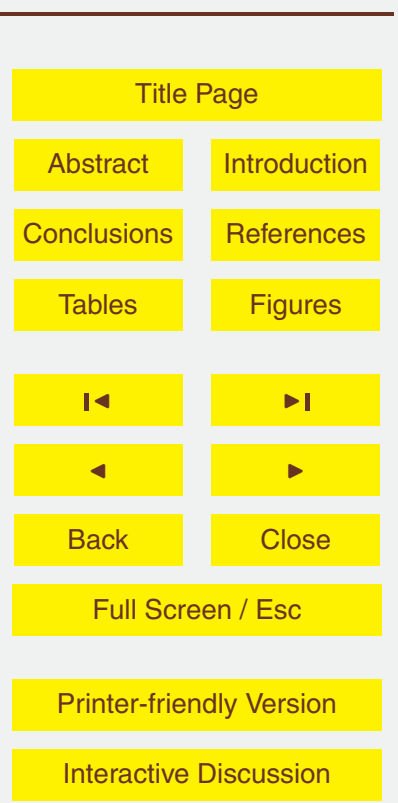




\section{Study area}

The study area of Qiaozhuang town (Qingchuan county) is located at the north-east part of Sichuan basin, more than $250 \mathrm{~km}$ NE of Yingxiu epicenter of Wenchuan earthquake, where the middle mountains and valley terraces are the main landforms. Even 5 though the study area is far from the epicenter, the surface rupture of QingchuanPingwu fault was closed to the Qiaozhuan town which caused serious damage to buildings of urban zone and mountains around the Qiaozhuan town. Investigation and research (Liu et al., 2009) was showing that three branches of Qingchuan-Pingwu fault were concealed in the cover layer and pass through the Qiaozhuan town (Fig. 1). Mt. Dong and Mt. Shizi are between the middle and the south branches of QingchuanPingwu fault, which the limestone and tabular phyllite are the main lithology. After Ms 8.0 Wenchuan earthquake, the strong aftershocks activity obviously occurred along the Qingchuan-Pingwu fault, where there were more than two thousands aftershocks until March 2009, which the biggest magnitude was Ms 6.4. Thus this fault tectonic belt gradually developed a middle and strong seismogenic zone. The seismic cracks and rock falls which had further deformation under strong aftershocks threated the safety of the residents around the city. Based on the beneficial aftershock monitoring period and the reality needs of slope seismic response evaluation, a systemic slope dynamic response monitoring was conducted at the Mt. Dong and Mt. Shizi, where five adits were excavated on different elevations within $15 \mathrm{~m}$ depth (Figs. 2 and 3 ), three of those (Q3, Q4 and Q6) located at Mt. Dong, others (Q8 and Q9) located at Mt. Shizi. All the monitoring sites are weak weathering rock which excepted the Q3 site is tabular phyllite lithology, other sites are limestone lithology. Acceleration sensors were emplaced in the adit with the detailed location as follows (Fig. 3): (1) Q3 (788 m): about $6 \mathrm{~m}$ above the where is located at the middle part of Mt. Dong, distance from the slope free surface was about $6 \mathrm{~m}$; (3) Q6 (962 m): near the top of Mt. Dong, distance from the slope free surface is about $7 \mathrm{~m}$; (4) Q8 (893 m): where is located at the middle of Mt. Shizi, dis-

NHESSD

2, 4135-4161, 2014

The slope seismic response monitoring of Wenchuan

Y. H. Luo et al.

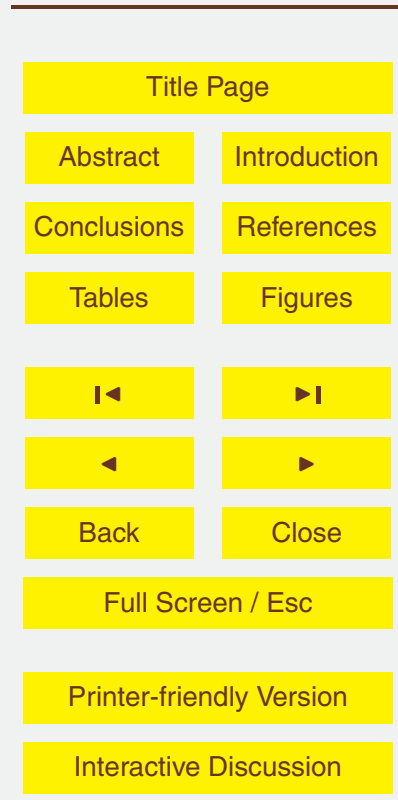


tance from the slope free surface is about $7 \mathrm{~m}$; (5) Q9 (962 m): near the top of Mt. Shizi, distance from the slope free surface is about $8 \mathrm{~m}$. The seismic monitoring instruments were composed of 941B seismic receiver and G01-16 data collecting system, which made by Institute of Engineering Mechanics, China Earthquake Administration. More 5 information can get from the sales Network (http://www.yangxs.com/). From 2009 to 2010 those five monitoring stations recorded nearly 60 aftershocks of low-moderate energy $\left(M_{L} \leq 5.2\right)$, but only nine events triggered all five stations, thirteen aftershocks triggered more than three stations, other aftershocks triggered less than three stations. So in this paper we analyzed twenty two typical events of triggering more than three stations (Table 1), whose magnitude varied between $2.3 \sim 5.2$ and epicentral distance was from a few to $45 \mathrm{~km}$. All the source parameters were taken from the China earthquake data center (http://data.earthquake.cn). The aftershocks distribution characteristics and typical waveforms of monitoring sites were showing the Figs. 4 and 5 respectively.

\section{PGA amplification effect}

In general, the peak ground acceleration (PGA) is an important parameter for evaluation the intensity magnitude of earthquake, which is usually regarded as a variable characterizing the inertia force caused by an earthquake on slope seismic response. Thus, the amplification effect of PGA is one of the most important factors of evaluation slope stability. At the beginning of analysis, all waveforms were filtering with $40 \mathrm{~Hz}$ cut-off frequency. Because of Q3 station is only several meters relative to the riverbed, which is as a reference station. The amplification factor of other monitoring stations of the same aftershock was calculation in the east-west component, north-south component and vertical component. Otherwise the synthesis peak ground acceleration
NHESSD

2, 4135-4161, 2014

The slope seismic response monitoring of Wenchuan

Y. H. Luo et al.

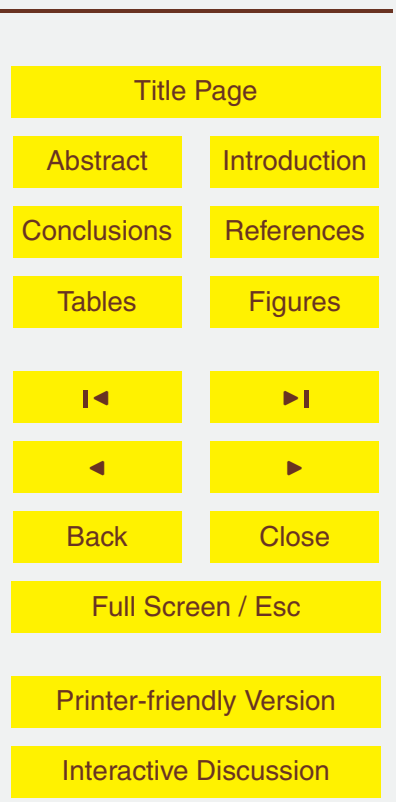


$\mathrm{PGA}_{\mathrm{T}}=\operatorname{Max}\left(\sqrt{a_{\mathrm{E}-\mathrm{W}}(i)^{2}+a_{\mathrm{N}-\mathrm{S}}(i)^{2}+a_{\mathrm{U}-\mathrm{D}}(i)^{2}}\right)$ which were used to analyze the synthesis component amplification factors comparison with the single component. Due to the relative-height-to-riverbed of slope monitoring sites on both sides is nearly close, so the calculation of amplification factor curves was as a comparison of slope seismic response on both sides mountain.

\subsection{Mountain Dong amplification effect characteristics}

Mt. Dong is a thin convex mountain that the geo-hazards distribution characteristics during Wenchuan earthquake had obvious topography amplification effect. The Q4 and Q6 monitoring stations are $89 \mathrm{~m}$ and $180 \mathrm{~m}$ height respectively relative to the riverbed.

10 The peak horizontal acceleration (PHA) amplification factor curves of the same events are showing that the middle height of Mt. Dong slope is more amplification than the maximum height (Fig. 6), which the amplification factor curves showing an outwardly convex response characteristics along with the relatively height changes. The biggest amplification factor of Q4 is 2.48 in north-south direction, while the biggest factor of Q6

15 is 1.48 as the same direction of Q4. Statistics calculation showed that the amplification factor $>1.0$ occupied $86 \%$ of Q4 in NS components is more than $36 \%$ in the EW components, while those amplification factor occupied $18 \%$ of Q6 in NS components more than none factor $>1.0$ in EW components. In summary indicated that the slope of Mt. Dong not only had amplification effect, but also had directional characteristics. Different from the PHA amplification characteristics that the peak vertical acceleration (PVA) showed the attenuation in the middle height of Mt. Dong, which the amplification factor curves showed an internal concave along with the relatively height changes. Compared to Q4 that all PVA ratios were less than 1.0, the Q6 amplification factor $>1.0$ occupied $60 \%$ of statistic data which the biggest amplification factor was 1.84 . It can get the conclusion that the monitoring site of Q4 is only amplified in the horizontal component, which the amplification factor is between $1.0 \sim 2.5$. As a comparison of single component, the calculation of synthesis values of monitoring data to analyze the amplification

NHESSD

2, 4135-4161, 2014

The slope seismic response monitoring of Wenchuan

Y. H. Luo et al.

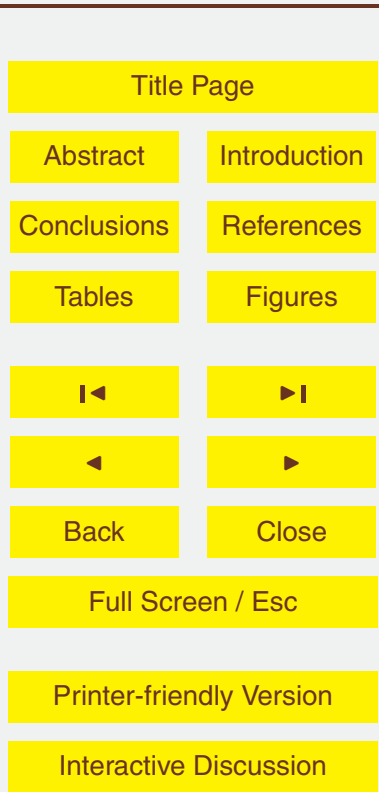


factor curves (Fig. 7). The horizontal components synthesis amplification factor curves showed the similar law as the single horizontal component, but the biggest amplification factor was 1.58 smaller than the latter. Meanwhile three components synthesis amplification factor was smaller than horizontal synthesis values which the curves had 5 the same regular. It is suggested that the slope amplification effect dominated by the horizontal component and the relative-height-to-riverbed may be a factor to interpret the amplification effect of mountain slope.

\subsection{Mountain Shizi amplification effect characteristics}

Mt. Shizi is located in the southwest of Qiaozhuang town, which the mountain ridge 10 elongated nearly east-west direction. The narrow ridge and hilltop were shattered crack or triggered rock falls under the strong Wenchuan earthquake. But the monitoring sites of Q8 and Q9 are not located in those protruding terrain parts, which the middle and top relative height is similar as the Mt. Dong. Compared to the same reference station (Fig. 6), the PHA amplification factors showed attenuation in the middle monitoring much bigger than the former which the biggest amplification factor was 1.25 , while the PVA amplification factors curves showed the internal concave along with the relatively height changes. In summary indicated that the monitoring site seismic amplification effect of Q9 was stronger than the Q8. For further comparison analysis the amplification effect with the single component, synthesis values of horizontal and vertical component were showing the similar response characteristics as the single horizontal acceleration, which suggested that the horizontal acceleration was the main dynamic feature during the earthquake processes.

\subsection{The PGA amplification effect comparison}

25 The monitoring sites of Mt. Dong and Mt. Shizi amplification effect calculation showed that the similar height of relative to riverbed had different seismic response in the mid-
NHESSD

2, 4135-4161, 2014

The slope seismic response monitoring of Wenchuan

Y. H. Luo et al.

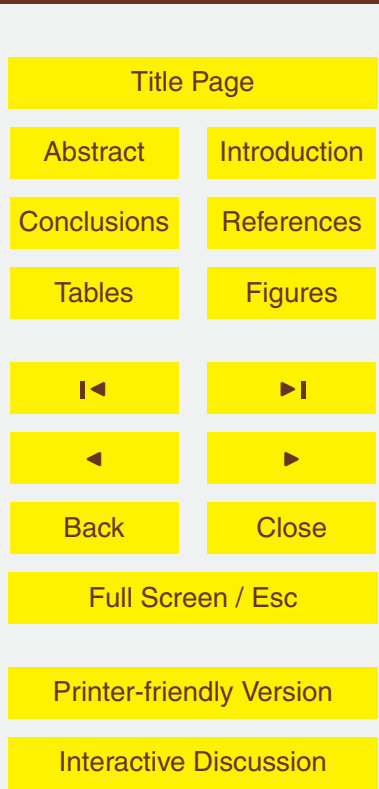

Interactive Discussion 
dle sites of slope on both sides. Actually during Wenchuan earthquake, the remote sensing interpretation statistics indicated that more serious damage induced by strong main earthquake between $650 \sim 2000 \mathrm{~m}$ on river bank, among those the most serious damage was between the $1000 \sim 1500 \mathrm{~m}$ (Huang et al., 2009). Moreover, the seismic geohazards investigation statistics of Shiting river, Mianyuan river, Chaping river and Jushui river showed that the number of geohazards were gradually increased along with the relativity height to riverbed increasing, but when the height more than $200 \mathrm{~m}$ the number of geohazards were gradually decrease (Li, 2012). Thus the Mt. Dong amplification factor curves characteristics is more correspond with the geohazards distribution statistics regular which can be used to interpret the distribution of earthquaketriggered geohazards in Wenchuan earthquake. In the case of study area, the middle monitoring sites on both sides also had different failure phenomenon which the rock falls and cracks around Q4 station were more serious than Q8 station. It is suggested that the site seismic response of Q4 is more intense than Q8 consistent with the monitoring results. Not only that the amplification effect indicates that the Q4 is also more intense than others, which the synthesis component ratios of Q4 with other stations are between $1.0 \sim 6.0$ (Fig. 8). Comprehensive analysis indicated that the middle site of Mt. Dong had the strongest amplification in the horizontal, then the Q6 and Q9 sites had slight amplification effect in vertical component. A frequency-domain parametric study results show that the peak amplification of motion at the crest of a slope occurs at a normalized frequency $H / \lambda=0.2$, where the $H$ is the height and $\lambda$ is the wavelength of the motion (Ashford et al., 1997). We can give the velocity approximate values of $S$ wave is about $3.0 \mathrm{~km} \mathrm{~s}^{-1}$, according to the formula $V=\lambda \times f$ and the main frequencies average statistics (Fig. 9), which the peak amplification is $86.71 \mathrm{~m}$ very closer to $89 \mathrm{~m}$ of relative height to the riverbed at Q4, thus we have the reason to infer the relative position in the valley to be an important factor of amplification effect.

\section{NHESSD}

2, 4135-4161, 2014

The slope seismic response monitoring of Wenchuan

Y. H. Luo et al.

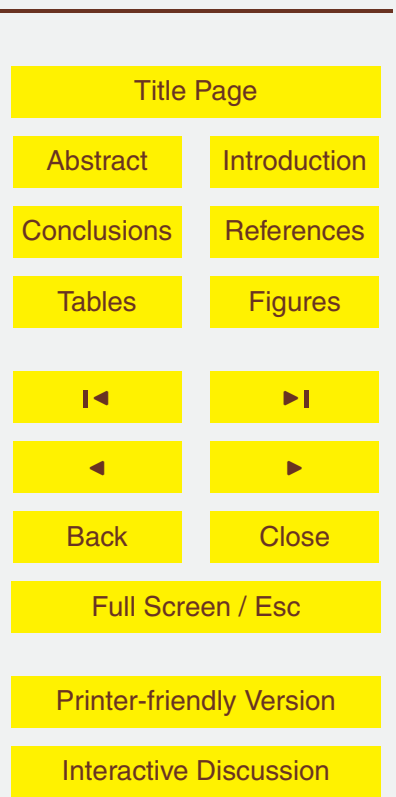




\section{Arias intensity (la) amplification effect}

Arias intensity (la) is a time-domain method parameter to describe the damage potential of ground motion proposed by arias (Arias, 1970), which is proportional to the integral of the square of the acceleration according to the following equation:

${ }_{5} I_{a}=\frac{\pi}{2 g} \int_{0}^{t_{0}} a^{2}(t) \mathrm{d} t$

In the above formula, the $a(t)$ is showing the acceleration, $t_{0}$ is the duration of ground motion and the $g$ is showing the acceleration of gravity. The calculation results indicated that the horizontal and vertical la amplification factor curves had the similar amplification effect as the PGA in Mt. Dong and Mt. Shizi. Only when the amplification factor is greater than 1.0 that the la ratios are bigger than PGA, conversely the la factor is less than PGA ratio (Fig. 10). The biggest amplification factor of la is 3.47 in horizontal direction at Q4 station in Mt. Dong, while the biggest amplification factor is 1.8 in vertical direction at Q9 station in Mt. Shizi.

\section{Horizontal to vertical spectral ratios (HVSR)}

15 The horizontal to vertical spectral ratio (HVSR) was first suggested in 1970 by Nogoshi (Nogoshi and Igarashi, 1970), Nakamura promoted this method to estimate site response characteristics with ground pulsation of surface station (Nakamura, 1989). The technique of HVSR was based on the assumption that the vertical component of ground motion was scarcely modified by local site conditions. Before the analysis, the data was selected from $S$ waves reach moment and the horizontal component was equal to $\mathrm{H}(i)=\sqrt{a_{\mathrm{EW}(i)}{ }^{2}+a_{\mathrm{NS}(i)^{2}}{ }^{2}}$. The same aftershock calculation comparison shows that the HVSR curves of Q4 at Mt. Dong are more amplification than the other two
NHESSD

2, 4135-4161, 2014

The slope seismic response monitoring of Wenchuan

Y. H. Luo et al.

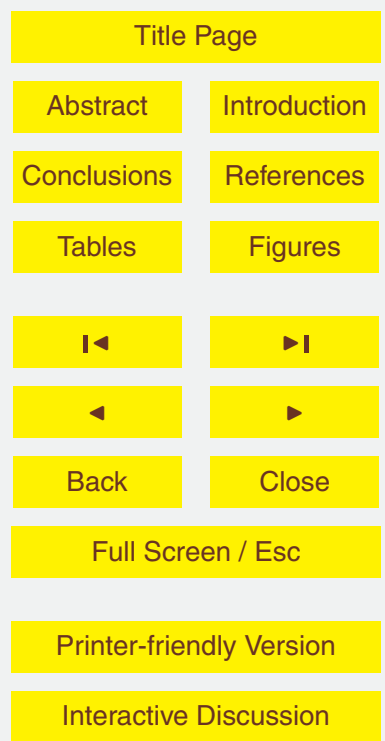


stations (Fig. 11). What's more that the amplification factors of $Q 4$ are fluctuation with the different dominant frequency such as $3 \mathrm{~Hz}$ and $6 \mathrm{~Hz}$, which the biggest amplification factor is between $4.5 \sim 8.0$. On the other side slope of Mt. Shizi, a comparison of HVSR curves indicate that around $5 \mathrm{~Hz}$ the peak values of Q8 are bigger than other 5 stations, which the biggest amplification factor is between $4.0 \sim 6.3$ (Fig. 12). On the other hand, the HVSR curves show a single dominant frequency around $10 \mathrm{~Hz}$, which the biggest amplification factor can reach 14.0. Comprehensive analysis shows that the amplification factors in the middle of slope fluctuate with the frequencies generate more peak values than other monitoring sites. Otherwise the amplification factors of 10 HVSR are bigger than the PGA and la analysis results.

\section{Results and discussion}

\subsection{Results}

Based on the slope failure during Wenchuan earthquake and aftershocks occurred around the study area, a field monitoring of slope inside seismic response had been conducted in the Mt. Dong and Mt. Shizi. Five adits had been excavated in different elevation for observation. This field monitoring stations had been emplaced inside of the slope about $7 \mathrm{~m}$ distance from the free surface. 22 typical aftershocks of more than 3 stations acquiring had been presented on the seismic behavior of the rock slope on both sides of symmetrical valley with the similar relative height to riverbed. We can get the following results:

1. Q4 station had obvious topography amplification effect which the peak horizontal acceleration amplification factor is between $1.0 \sim 2.5$.

2. On both sides slope, at the middle height monitoring sites the vertical component showed attenuation effect, but at the top monitoring sites that the peak vertical acceleration had amplification effect with the factor of $1.0 \sim 1.84$.
NHESSD

2, 4135-4161, 2014

The slope seismic response monitoring of Wenchuan

Y. H. Luo et al.

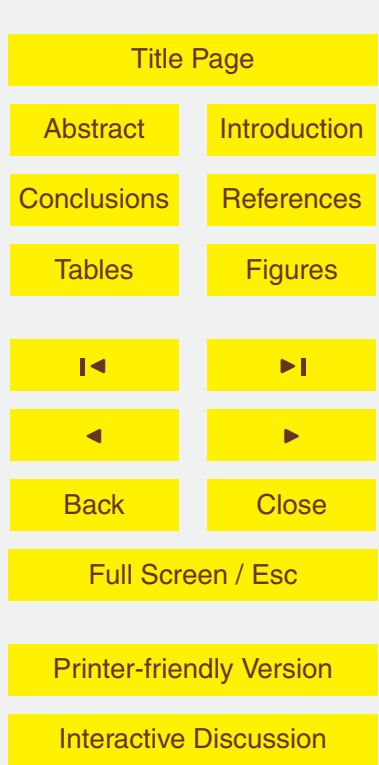

4144 
3. Comprehensive research indicates that the relative height to riverbed is an important factor of amplification effect in mountain slope seismic response.

4. The arias intensity has the same amplification characteristics as the PGA calculation, which the biggest amplification factor is 3.47 in north-south component.

5. The synthesis values calculation results suggest that the horizontal dynamic effect is stronger than vertical during the earthquake process.

6. HVSR calculation results show that there are multiple peak values of amplification factors at Q4 fluctuate with the dominant frequency, moreover the amplification factor is generally bigger than PGA and la ratios.

\subsection{Discussion}

Q3 station as a reference because of it has lowest relative height to riverbed, even though it has different lithology of Phyllite and close to the QC-PW fault, which the HVSR calculation results show the resonance frequency very focus in a fixed frequency around $10 \mathrm{~Hz}$ and the spectral ration curve has simple peak value. Otherwise, due to the damage of combined sensors in NS component at Q9 station, so only the east-west horizontal and vertical component are calculation to analysis the amplification effect, which also can reflect the sites seismic response. A comparison of monitoring sites show that Q4 has obvious amplification effect in the horizontal component, not in the vertical component. On the contrary, the Q6 has obvious amplification effect in the vertical component. A different relative height to the riverbed on the same slope shows the different slope seismic response. It means that the dominant vibration of particle motion is different at those monitoring sites. Based on seismic wave propagation characteristics, the body waves are the main mode of propagation inside the mountain which contained two types of $P$ wave and $S$ wave, but when the seismic wave propagate to the surface such as the mountain top, the surface waves are the main mode of propagation which contain another two types of Love wave and Rayleigh wave. Generally, the

\section{NHESSD}

2, 4135-4161, 2014

The slope seismic response monitoring of Wenchuan

Y. H. Luo et al.

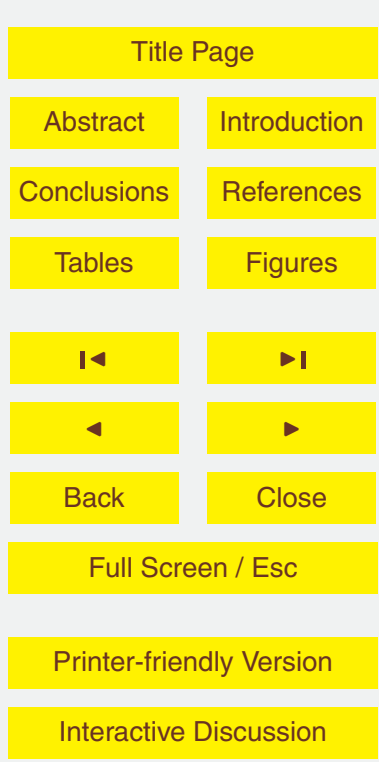


$P$ wave cause the up and down vibration and the $S$ wave cause horizontal vibration, combined the topography characteristics of Q4 which the lateral topography is more conducive to vibration than the longitudinal slope, thus the horizontal component has amplification effect. But at the mountain top of Q8 which the longitudinal topography 5 is more conducive to vibration, so the vertical component of Q8 amplify obviously. The same reason can also interpret the attenuation and amplification effect on Mt. Shizi. With regard to HVSR, which is based on the assumption of scarcely modified of vertical component, the result of calculation is mainly showing the resonance frequency. Even though the PGA analysis shows that the vertical component has obvious ampli10 fication or attenuation, the amplification factor of HVSR just reflects the amplification with the frequency, which is also useful for us to analysis the slope seismic response.

\subsection{Perspectives}

This paper reports a monitoring progress of rock slope seismic response, series of aftershocks analysis shows a typical amplification effect of slope seismic response. But there are only two monitoring stations emplaced at the nearly $200 \mathrm{~m}$ height slope, the monitoring results do not fully reflect the amplification regular with the relative height to the riverbed, so recently we have added another three stations between the Q4 and Q6 on Mt. Dong slope. The aim is to get more evidence of slope seismic amplification effect at different height.

\section{Conclusions}

From the preceding results and discussion, we can make the following conclusions:

1. For both PHA and la, the amplification effect of Q4 is the strongest of all monitoring points, with the biggest amplification factor is 2.5 and 3.47 respective. In addition, the amplification effect of the horizontal component is stronger than that of the vertical component.
NHESSD

2, 4135-4161, 2014

The slope seismic response monitoring of Wenchuan

Y. H. Luo et al.

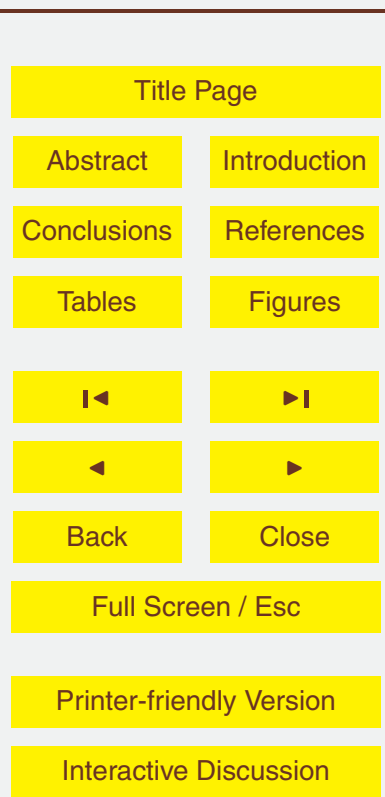


2. The vertical component had the similar seismic response regular with altitude increase of monitoring point, either in Mt. Dong or Mt. Shizi, which the attenuation effect of slopes middle elevation is due to the body waves propagation, but the amplification effect of mountain top elevation is due to the surface waves propagation.

3. The ground-motion amplification effect of $\mathrm{Q} 4$ shows correlation with the relative height to riverbed and the lateral topography. Note that the relative height calculation is based on the peak amplification of motion at the crest of a slope occurs at a normalized frequency $H / \lambda=0.2$ by Ashford et al. (1997). This indicates that the frequency of the seismic wave is an important factor of slope height amplification.

Acknowledgements. This research is financially supported by the China Geological Survey Bureau (Grant No. 1212010914010 and 1212011220154 ), the National Natural Science Foundation of China (Grant No. 41072231, Grant No. 41202211), the talent fund provided by the State Key Laboratory of Geo-environment Protection and Geo-hazard Prevention (Grant No.11900002247). The Master's degree participants Huhai Wang, Xiao Ma, Junsheng Yue who assisted in the execution of the monitoring are thanked sincerely. The authors also would like to give great thanks to Janusz Wasowski and other reviewers whose comments greatly improved the quality of the manuscript.

\section{References}

Arias, A.: A measure of earthquake intensity, in: Seismic Design for Nuclear Power Plants, MIT Press, Cambridge, Mass, 438-483, 1970.

Ashford, S. A., Sitar, N., Lysmer, J., and Deng, N.: Topographic effects on the seismic response of steep slopes, B. Seismol. Soc. Am., 87, 701-709, 1997.

Bouchon, M.: Effect of topography on surface motion, B. Seismol. Soc. Am., 63, 615-632, 1973.

Bouchon, M. and Barker, J. S.: Seismic response of a hill: the example of Tarzana, California, B. Seismol. Soc. Am., 86, 66-72, 1996.

\section{NHESSD}

2, 4135-4161, 2014

The slope seismic response monitoring of Wenchuan

Y. H. Luo et al.

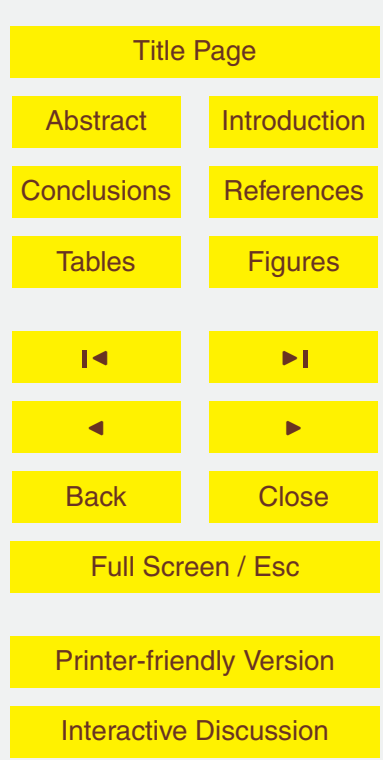


Davis, L. L. and West, L. R.: Observed effects of topography on ground motion, B. Seismol. Soc. Am., 63, 283-298, 1973.

Griffiths, D. W. and Bollinger, G. A.: The effect of Appalachlan mountain topography on seismic waves, B. Seismol. Soc. Am., 69, 1081-1105, 1979.

5 Huang, R. Q.: Geohazard Assessment of the Wenchuan Earthquake, Science and Technology Press, Beijing, 235-245, 2009.

Lee, S. J., Chan, Y. C., Komatitsch, D., Huang, B. S., and Tromp, J.: Effects of realistic surface topography on seismic ground motion in the Yangmingshan region of Taiwan based upon the spectral-element method and LiDAR DTM, B. Seismol. Soc. Am., 99, 681-693, 2008.

$10 \mathrm{Li}, \mathrm{G}$.: Failure mechanism of stratiform rock slope under strong earthquake, The PhD Thesis of Chengdu University of Technology, Chengdu, 34-35, 2012.

Liu, G. L., Li, Y. S., Chen, J., and Xie, L.: The problem of earthquake fault about Qiaozhuang town in the Qingchuan county after Wenchuan earthquake, J. Mt. Sci., 4, 496-500, 2009.

Nakamura, Y.: A method for dynamic characteristics estimations of subsurface using microtremors on the ground surface, Quart. Rep. Railway Tech. Res. Inst (RTRI), 30, 25-33, 1989.

Nogoshi, M. and Igarashi, T.: On the propagation characteristics estimation of subsurface using microtremors on the ground surface, J. Seismol. Soc. Jpn., 23, 264-280, 1970.

Wong, H. L. and Jennings, P. C.: Effects of canyon topography on strong ground motion, B. Seismol. Soc. Am., 65, 1239-1257, 1975.

\section{NHESSD}

2, 4135-4161, 2014

\section{The slope seismic response monitoring of Wenchuan}

Y. H. Luo et al.

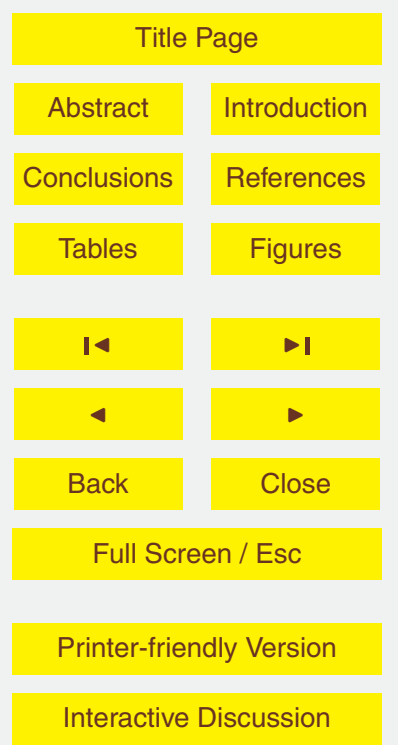




\section{NHESSD}

\section{2, 4135-4161, 2014}

Table 1. Main source parameters of typical aftershocks.

\begin{tabular}{|c|c|c|c|c|c|c|c|}
\hline Number & Original time & Magnitude & Longitude $\left({ }^{\circ}\right)$ & $\begin{array}{l}\text { Latitude }\left({ }^{\circ}\right) \\
\text { depth }(\mathrm{km})\end{array}$ & $\begin{array}{l}\text { Hypocenter } \\
\text { distance }(\mathrm{km})\end{array}$ & Epicentral & Azimuth $\left({ }^{\circ}\right)$ \\
\hline 1 & 7 Sep 2009 20:54:18.0 & $M_{\mathrm{L}} 2.4$ & 105.31 & 32.59 & 16 & 6.46 & 88.81 \\
\hline 2 & 12 Sep 2009 02:25:43.1 & $M_{\mathrm{L}} 3.3$ & 105.13 & 32.49 & 23 & 15.13 & 223.52 \\
\hline 3 & 12 Sep 2009 13:25:08.9 & $M_{\mathrm{L}} 2.7$ & 105.26 & 32.57 & 14 & 2.75 & 140.06 \\
\hline 4 & 19 Sep 2009 14:00:43.8 & $M_{\mathrm{L}} 2.8$ & 105.32 & 32.59 & 5 & 7.40 & 88.92 \\
\hline 5 & 19 Sep 2009 16:54:14.3 & Ms 5.2 & 105.56 & 32.90 & 8 & 45.68 & 40.64 \\
\hline 6 & 24 Sep 2009 05:02:58.7 & $M_{\mathrm{L}} 2.3$ & 105.26 & 32.55 & 15 & 4.65 & 157.70 \\
\hline 7 & 14 Oct 2009 16:03:05.1 & $M M_{L} 4.1$ & 105.37 & 32.58 & 23 & 12.19 & 94.57 \\
\hline 8 & 18 Oct 2009 04:59:55.6 & $M, 3.8$ & 104.99 & 32.43 & 10 & 29.45 & 233.25 \\
\hline 9 & 27 Oct 2009 17:56:39.1 & $M_{\mathrm{L}} 2.9$ & 105.36 & 32.58 & 16 & 11.19 & 95.00 \\
\hline 10 & 29 Oct 2009 21:28:00.5 & Ms 4.6 & 105.19 & 32.58 & 10 & 4.78 & 258.65 \\
\hline 11 & 7 Nov 2009 19:35:58.9 & $M_{\mathrm{L}} 3.2$ & 105.32 & 32.57 & 16 & 7.70 & 105.72 \\
\hline 12 & 23 Nov 2009 04:14:46.1 & $M_{\mathrm{L}} 3.1$ & 105.28 & 32.56 & 18 & 4.85 & 131.17 \\
\hline 13 & 08 Dec 2009 03:00:23.2 & $M_{\mathrm{L}} 3.4$ & 105.09 & 32.51 & 18 & 16.67 & 238.29 \\
\hline 14 & 08 Dec 2009 07:13:58.6 & $M=2.9$ & 105.28 & 32.58 & 19 & 3.77 & 105.07 \\
\hline 15 & 31 Dec 2009 19:06:33.7 & $M_{\mathrm{L}} 3.3$ & 105.27 & 32.56 & 17 & 4.19 & 139.79 \\
\hline 16 & 8 Jan 2010 01:01:25.5 & $M_{\mathrm{L}} 3.8$ & 105.15 & 32.42 & 23 & 20.55 & 204.58 \\
\hline 17 & 22 Jan 2010 04:10:35.2 & $M_{\mathrm{L}} 2.6$ & 105.30 & 32.58 & 5 & 5.16 & 100.12 \\
\hline 18 & 24 Jan 2010 02:28:39.8 & $M_{\mathrm{L}} 3.3$ & 105.35 & 32.61 & 22 & 10.49 & 76.77 \\
\hline 19 & 24 Jan 2010 19:01:07.6 & $M_{\mathrm{L}} 3.3$ & 105.26 & 32.56 & 17 & 3.65 & 151.14 \\
\hline 20 & 1 Mar 2010 14:24:54.1 & Ms 4.2 & 105.04 & 32.33 & 14 & 34.32 & 213.33 \\
\hline 21 & 10 Mar 2010 14:23:38.5 & $M_{\mathrm{L}} 3.8$ & 105.27 & 32.56 & 8 & 4.19 & 139.94 \\
\hline 22 & 30 May 2010 07:05:05.0 & $M_{\mathrm{L}} 3.8$ & 105.28 & 32.54 & 20 & 6.53 & 146.22 \\
\hline
\end{tabular}

The slope seismic response monitoring of Wenchuan

Y. H. Luo et al.

Title Page

\begin{tabular}{|c|c|}
\hline Abstract & Introduction \\
\hline Conclusions & References \\
\hline Tables & Figures \\
\hline I4 & \\
\hline & \\
\hline Back & Close \\
\hline Full Screen / Esc \\
\hline
\end{tabular}

ML means Magnitude Local, Ms means Magnitude Surface wave.

Printer-friendly Version

Interactive Discussion 


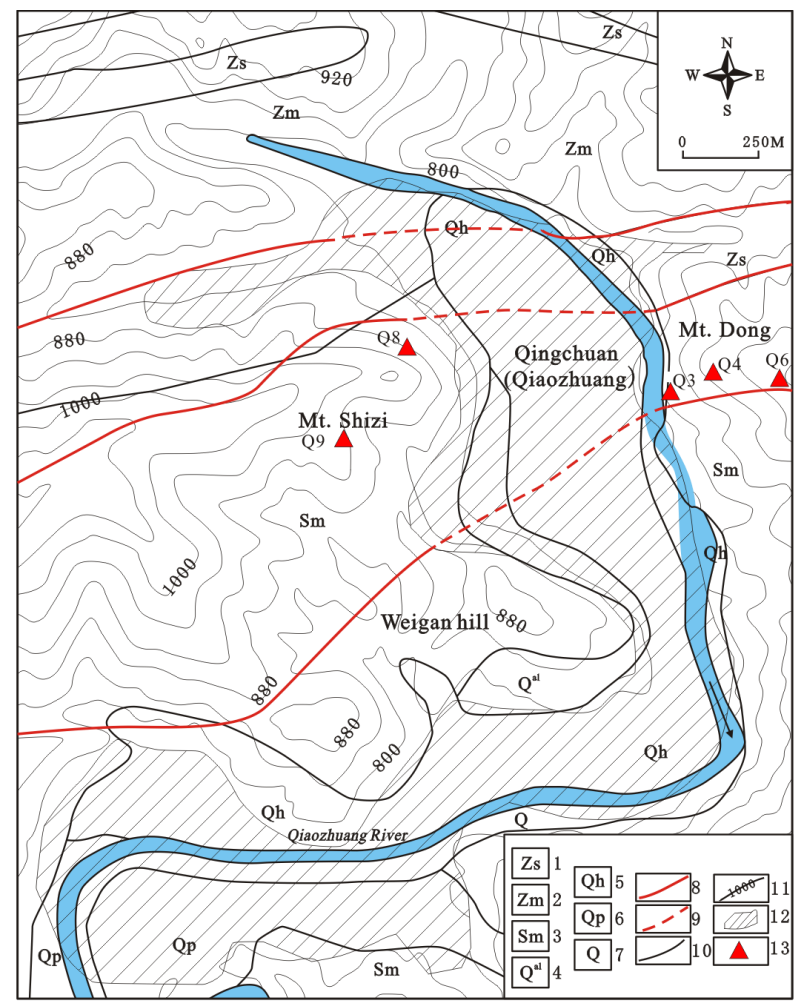

Figure 1. Geological map of the study area: the Qingchuan-Pingwu fault is composed by three branch faults (north, central and south); 1.Upper Sinian (limestone); 2. Lower Sinian (sandstone); 3. Lower Silurian(phyllite); 4. Quatermary (alluvium); 5. Quaternary-Holocene (alluvial deposits); 6. Quaternary-Pleistocene (alluvial deposits); 7. Quaternary(alluvial terrace); 8. Qingchuan-Pingwu Fault; 9. Speculation Fault; 10. Lithostratigraphic boundary; 11. Contour; 12. Main urban zone. 13. Monitoring point.

\section{NHESSD}

2, 4135-4161, 2014

The slope seismic response monitoring of Wenchuan

Y. H. Luo et al.

\begin{tabular}{|c|c|}
\hline \multicolumn{2}{|c|}{ Title Page } \\
\hline Abstract & Introduction \\
\hline Conclusions & References \\
\hline Tables & Figures \\
\hline I4 \\
\hline Back \\
\hline Full Screen / Esc \\
\hline Printer-friendly Version \\
\hline Interactive Discussion \\
\hline
\end{tabular}




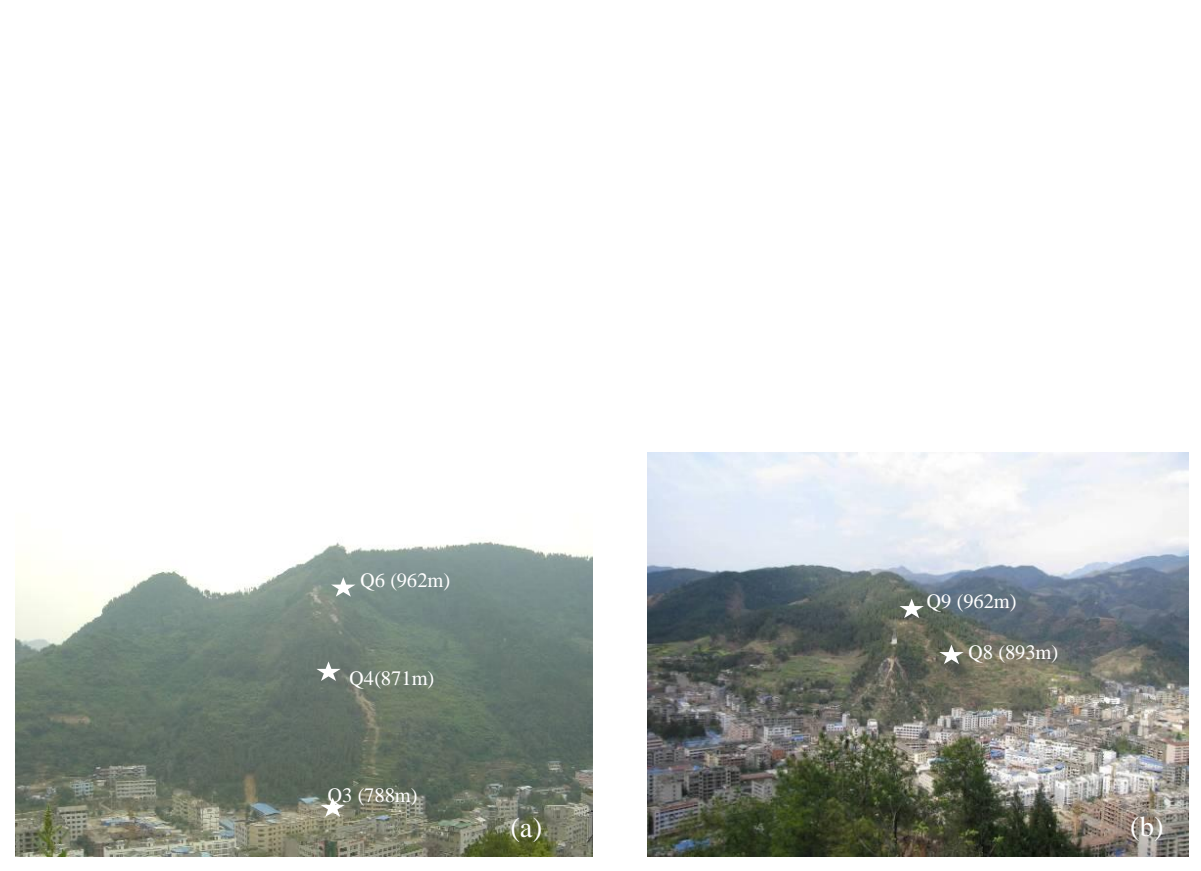

\section{NHESSD}

2, 4135-4161, 2014

\section{The slope seismic} response monitoring of Wenchuan

Y. H. Luo et al.

\begin{tabular}{|c|c|}
\hline \multicolumn{2}{|c|}{ Title Page } \\
\hline Abstract & Introduction \\
\hline Conclusions & References \\
\hline Tables & Figures \\
\hline I & \\
\hline & \\
\hline Back & Close \\
\hline
\end{tabular}

Full Screen / Esc

Figure 2. The location of five adits at Mt. Dong and Mt. Shizi: (a) the elevation of Q3, Q4 and Q6 at Mt. Dong, (b) the elevation of Q8 and Q9 at Mt. Shizi.

\section{Printer-friendly Version}

Interactive Discussion 


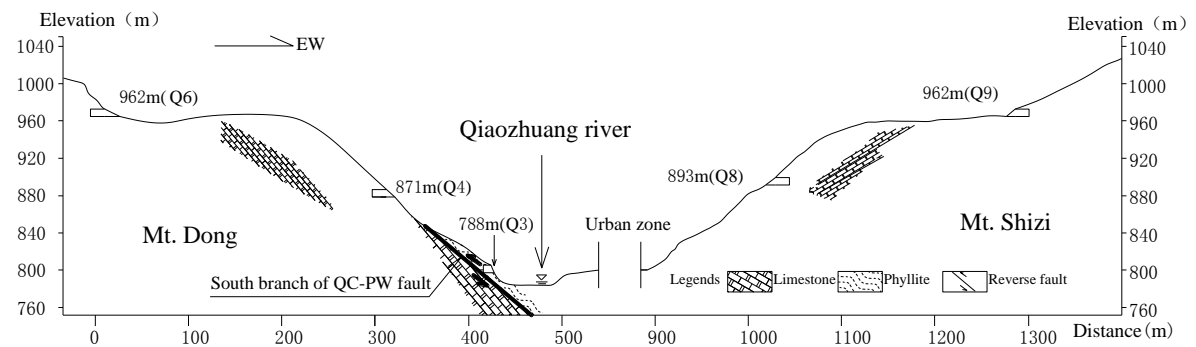

Figure 3. The cross section of monitoring sites.

\section{NHESSD}

2, 4135-4161, 2014

The slope seismic response monitoring of Wenchuan

Y. H. Luo et al.

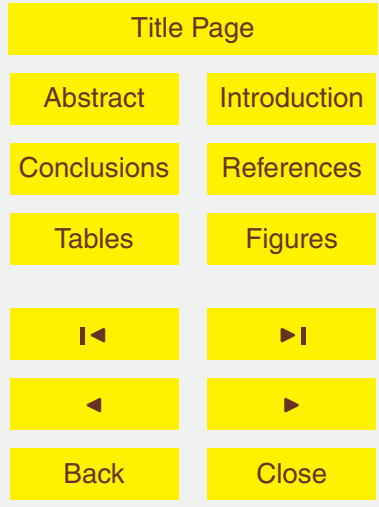

Full Screen / Esc

Printer-friendly Version

Interactive Discussion

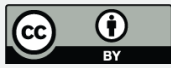




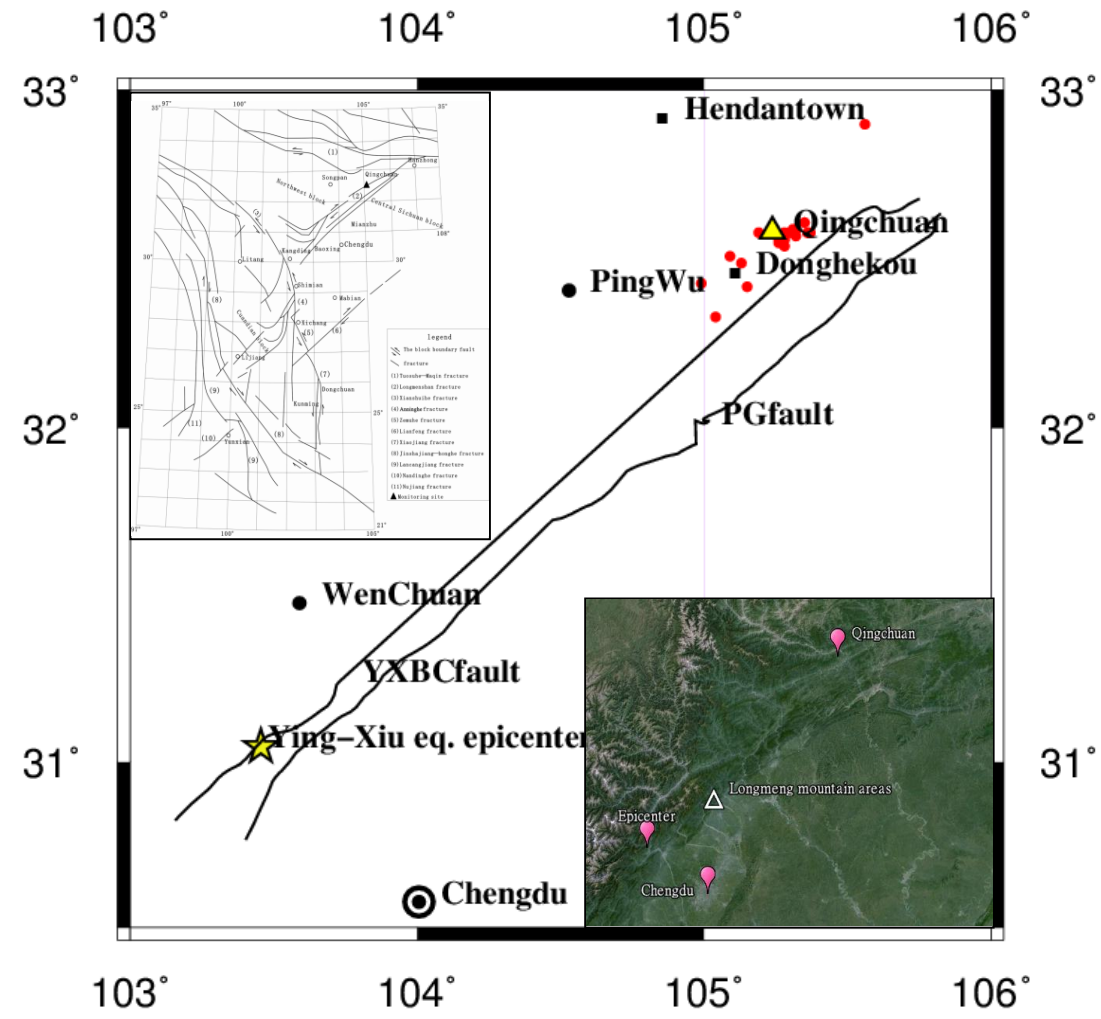

Figure 4. The location of the monitoring area: the yellow triangle showing the study area, the yellow five-pointed star showing the epicenter of Wenchuan earthquake, the red circle point showing the monitoring events, the YXBC-fault meaning the Yingxiu-Beichuan fault, PG-fault meaning the Penxian-Guanxian fault, the upper left corner showing the geotectonic feature of Longmen mountain, the lower right corner showing the location of monitoring point and Longmen mountain areas in Google earth.

\section{NHESSD}

2, 4135-4161, 2014

The slope seismic response monitoring of Wenchuan

Y. H. Luo et al.

\begin{tabular}{|c|c|}
\hline \multicolumn{2}{|c|}{ Title Page } \\
\hline Abstract & Introduction \\
\hline Conclusions & References \\
\hline Tables & Figures \\
\hline I4 & \\
\hline Back & Close \\
\hline Full Screen / Esc \\
\hline Printer-friendly Version \\
\hline Interactive Discussion
\end{tabular}



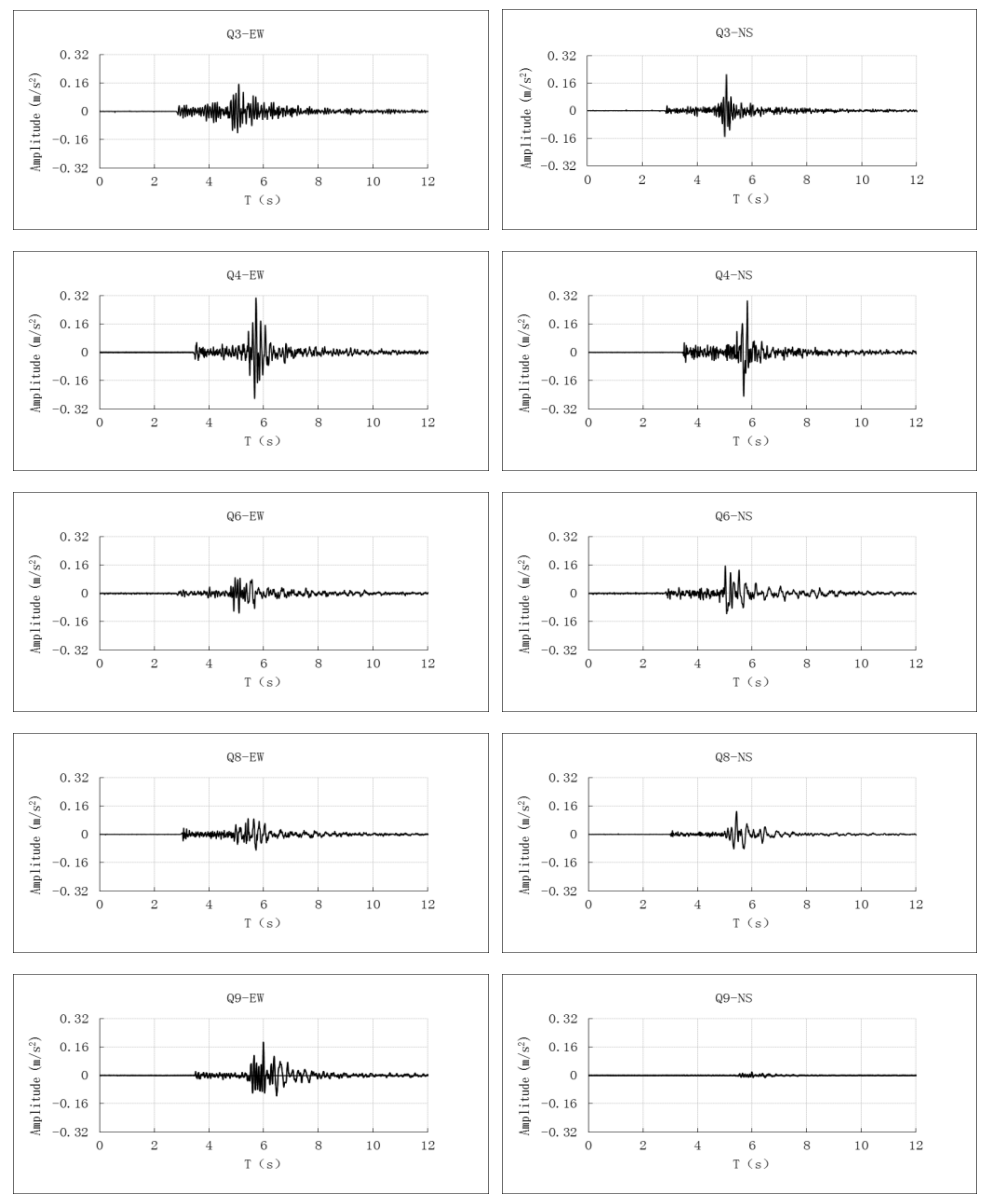

Figure 5. The east-west and north-south components accelerograms of the typical aftershocks: 14 October 2009 ML4.1.

\section{NHESSD}

2, 4135-4161, 2014

The slope seismic response monitoring of Wenchuan

Y. H. Luo et al.

\begin{tabular}{|c|c|}
\hline \multicolumn{2}{|c|}{ Title Page } \\
\hline Abstract & Introduction \\
\hline Conclusions & References \\
\hline Tables & Figures \\
\hline I4 & \\
\hline & \\
\hline Back & Close \\
\hline Full Screen / Esc \\
\hline Printer-friendly Version \\
\hline Interactive Discussion
\end{tabular}



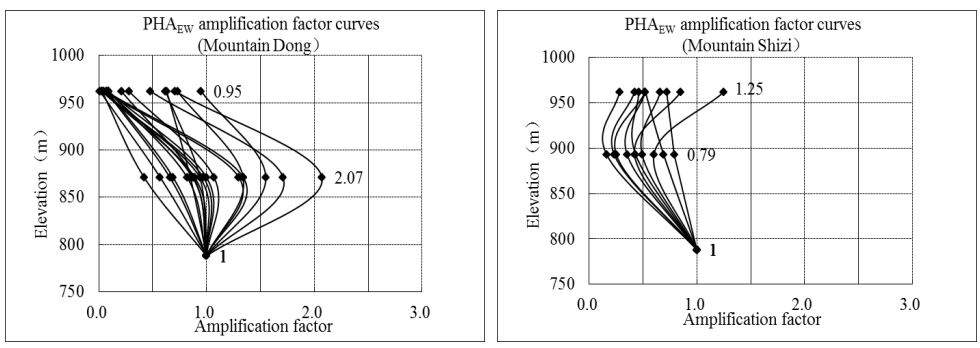

\section{NHESSD}

2, 4135-4161, 2014

The slope seismic response monitoring of Wenchuan

Y. H. Luo et al.
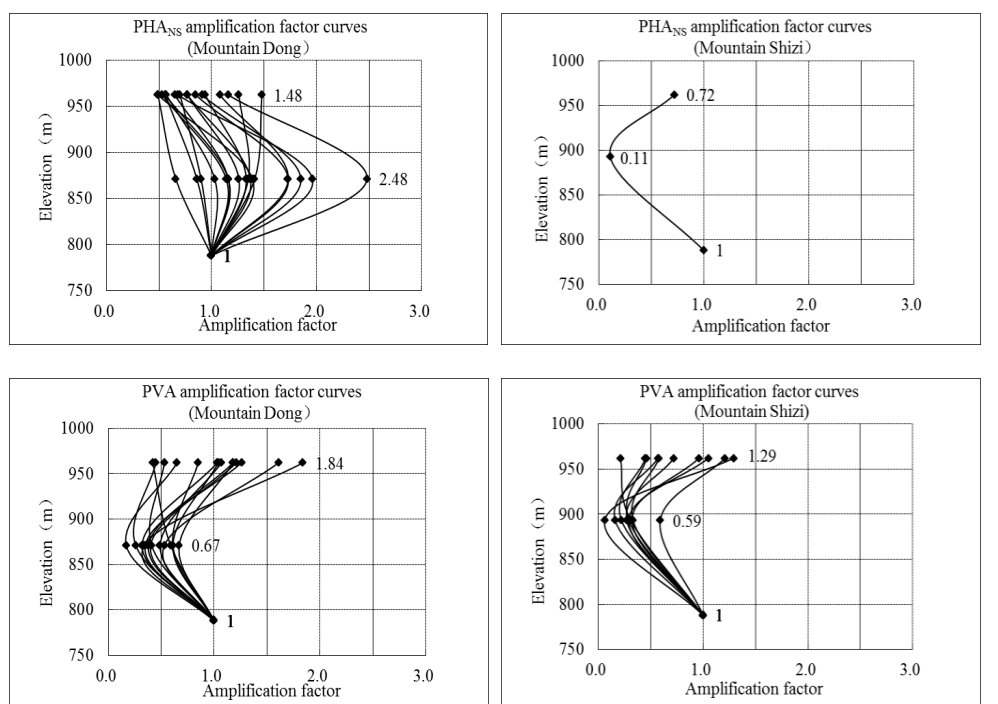

Figure 6. The PHA and PVA amplification factor curves at Mt. Dong and Mt. Shizi (Q3 was the reference station).

\begin{tabular}{|c|c|}
\hline \multicolumn{2}{|c|}{ Title Page } \\
\hline Abstract & Introduction \\
\hline Conclusions & References \\
\hline Tables & Figures \\
\hline I & \\
\hline & \\
\hline Back & Close \\
\hline Full Screen / Esc \\
\hline
\end{tabular}

Printer-friendly Version

Interactive Discussion 

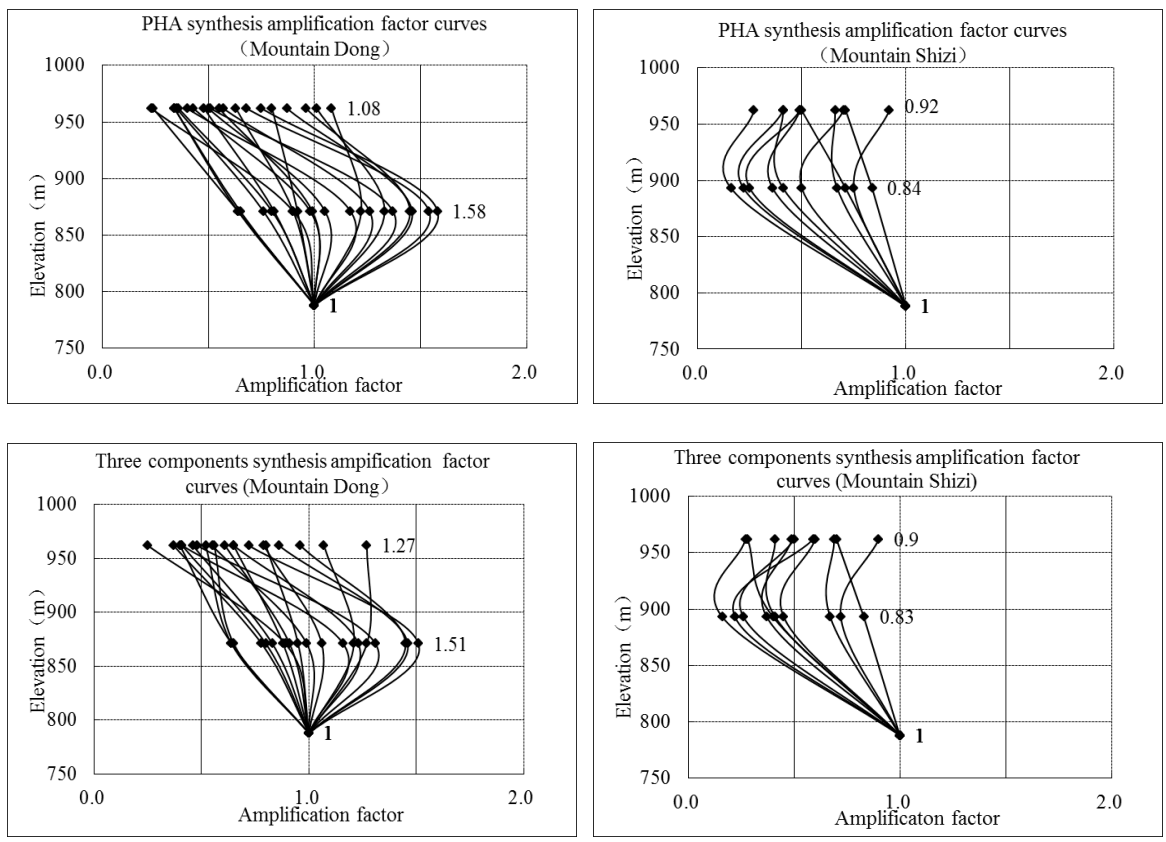

Figure 7. The Synthesis amplification factor curves at Mt. Dong and Mt. Shizi (Q3 was the reference station).

\section{NHESSD}

2, 4135-4161, 2014

\section{The slope seismic response monitoring of Wenchuan}

Y. H. Luo et al.

Title Page

\begin{tabular}{|c|c|}
\hline Abstract & Introduction \\
\hline Conclusions & References \\
\hline Tables & Figures \\
\hline & \\
\hline B & \\
\hline & \\
\hline Back & Close \\
\hline Full Screen / Esc \\
\hline
\end{tabular}

Printer-friendly Version

Interactive Discussion

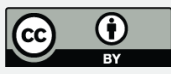



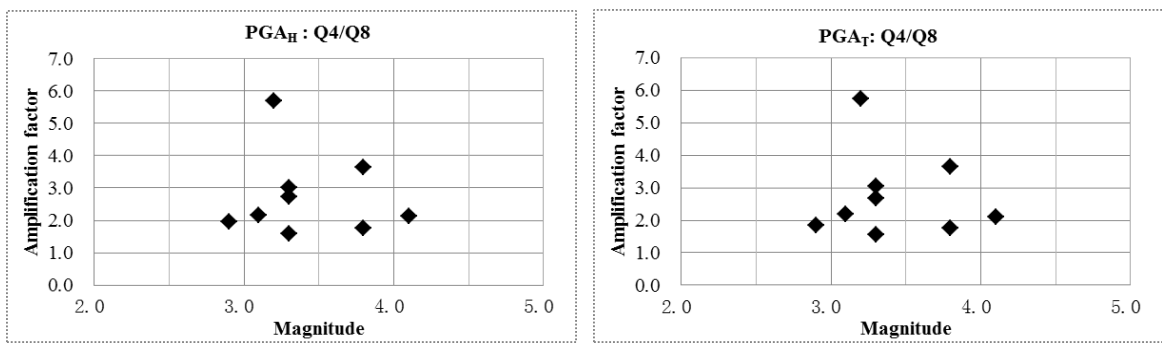

\section{NHESSD}

2, 4135-4161, 2014

The slope seismic response monitoring of Wenchuan

Y. H. Luo et al.
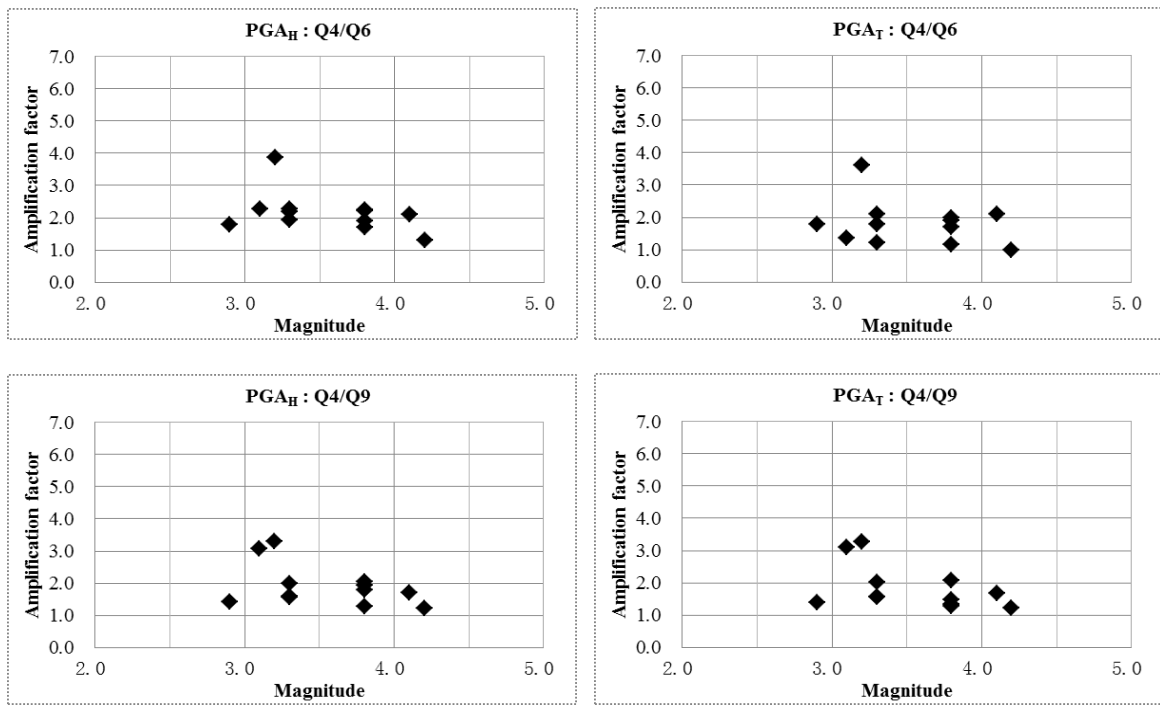

Figure 8. The ratios of $Q 4$ synthesis component with other monitoring stations: $P G A_{H}$ : peak ground acceleration of horizontal synthesis component; $P G A_{T}$ : peak ground acceleration of three synthesis component.

Title Page

\begin{tabular}{|c|c|}
\hline Abstract & Introduction \\
\hline Conclusions & References \\
\hline Tables & Figures \\
\hline I4 & - I \\
\hline 4 & \\
\hline Back & Close \\
\hline Full Screen / Esc
\end{tabular}

Printer-friendly Version

Interactive Discussion 

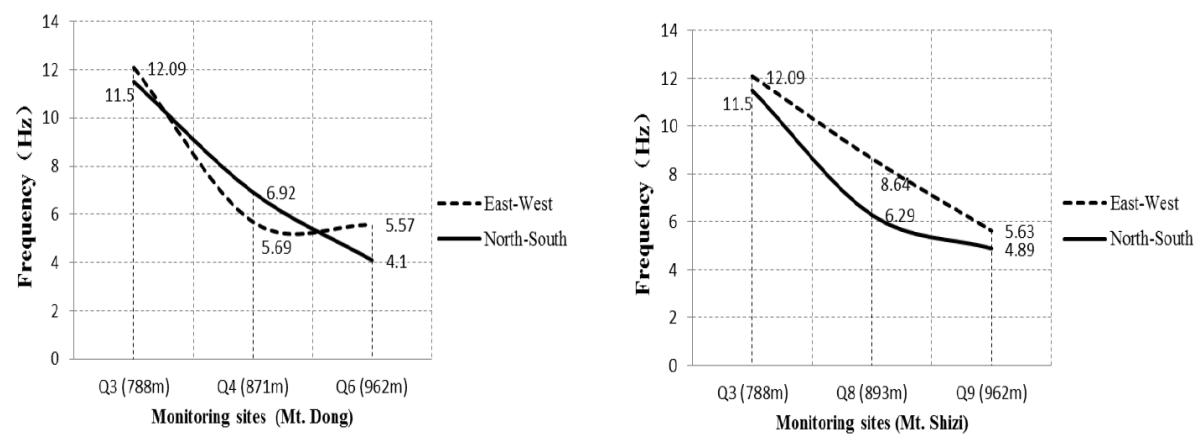

\section{NHESSD}

2, 4135-4161, 2014

\section{The slope seismic response monitoring of Wenchuan}

Y. H. Luo et al.

\begin{tabular}{|c|c|}
\hline \multicolumn{2}{|c|}{ Title Page } \\
\hline Abstract & Introduction \\
\hline Conclusions & References \\
\hline Tables & Figures \\
\hline I4 & \\
\hline & \\
\hline Back & Close \\
\hline Full Screen / Esc \\
\hline Printer-friendly Version \\
\hline Interactive Discussion
\end{tabular}

Figure 9. The main frequencies average values variation characteristics of horizontal component in Mt. Dong and Mt. Shizi monitoring sites.

Interactive Discussion 

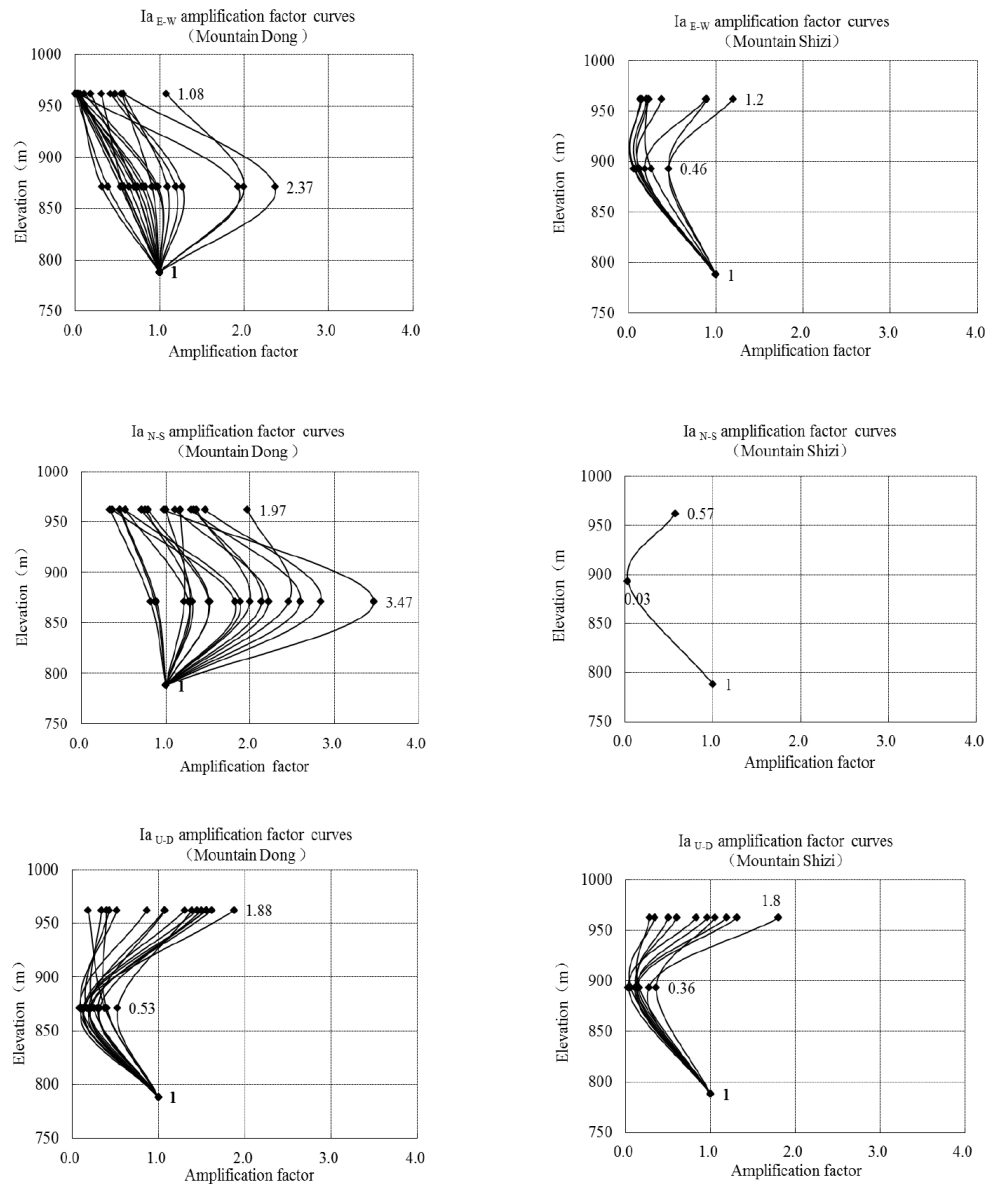

Figure 10. The Arias intensity amplification factor curves at Mt. Dong and Mt. Shizi (Q3 was the reference station).

\section{NHESSD}

2, 4135-4161, 2014

The slope seismic response monitoring of Wenchuan

Y. H. Luo et al.

Title Page

\begin{tabular}{|c|c|}
\hline Abstract & Introduction \\
\hline Conclusions & References \\
\hline Tables & Figures \\
\hline I4 & \\
\hline 4 & \\
\hline Back & Close \\
\hline Full Screen / Esc \\
\hline Printer-friendly Version \\
\hline Interactive Discussion
\end{tabular}

(c) (i) 

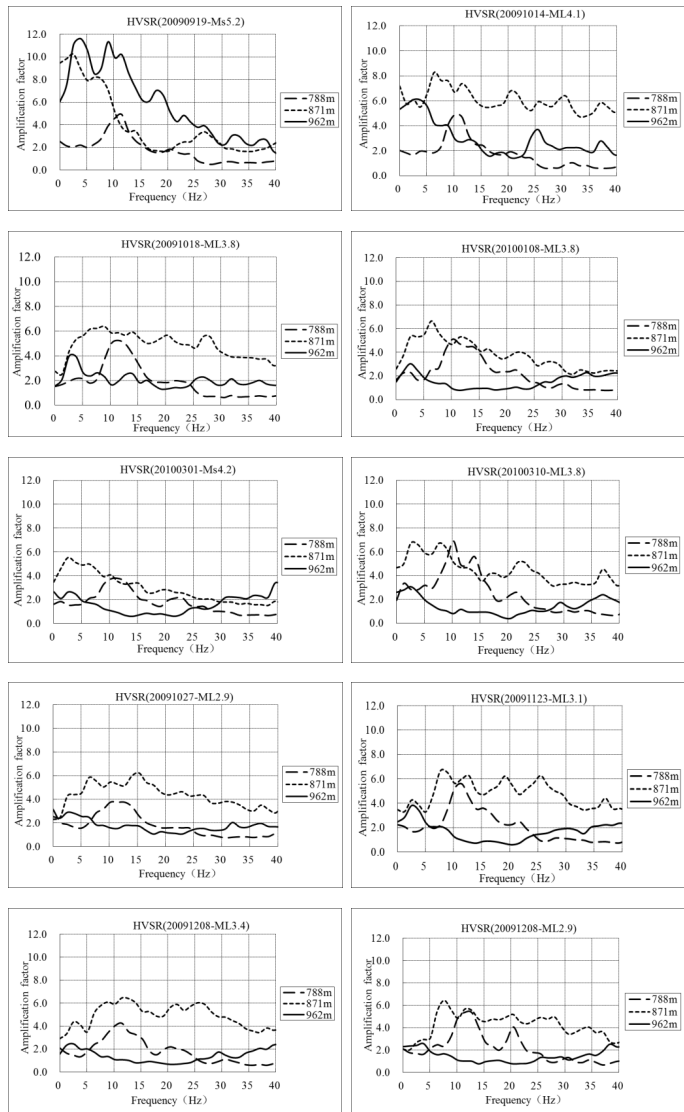

Figure 11. Horizontal to vertical spectral ratio (HVSR) of typical aftershocks comparison at Mt. Dong: $788 \mathrm{~m}$ equal to Q3 station, $871 \mathrm{~m}$ equal to $\mathrm{Q} 4$ station, $962 \mathrm{~m}$ equal to $\mathrm{Q} 6$ station.

\section{NHESSD}

2, 4135-4161, 2014

The slope seismic response monitoring of Wenchuan

Y. H. Luo et al.

Title Page

\begin{tabular}{|c|c|}
\hline Abstract & Introduction \\
\hline Conclusions & References \\
\hline Tables & Figures \\
\hline I & \\
\hline & \\
\hline Back & Close \\
\hline Full Screen / Esc \\
\hline Printer-friendly Version \\
\hline Interactive Discussion
\end{tabular}

Interactive Discussion 


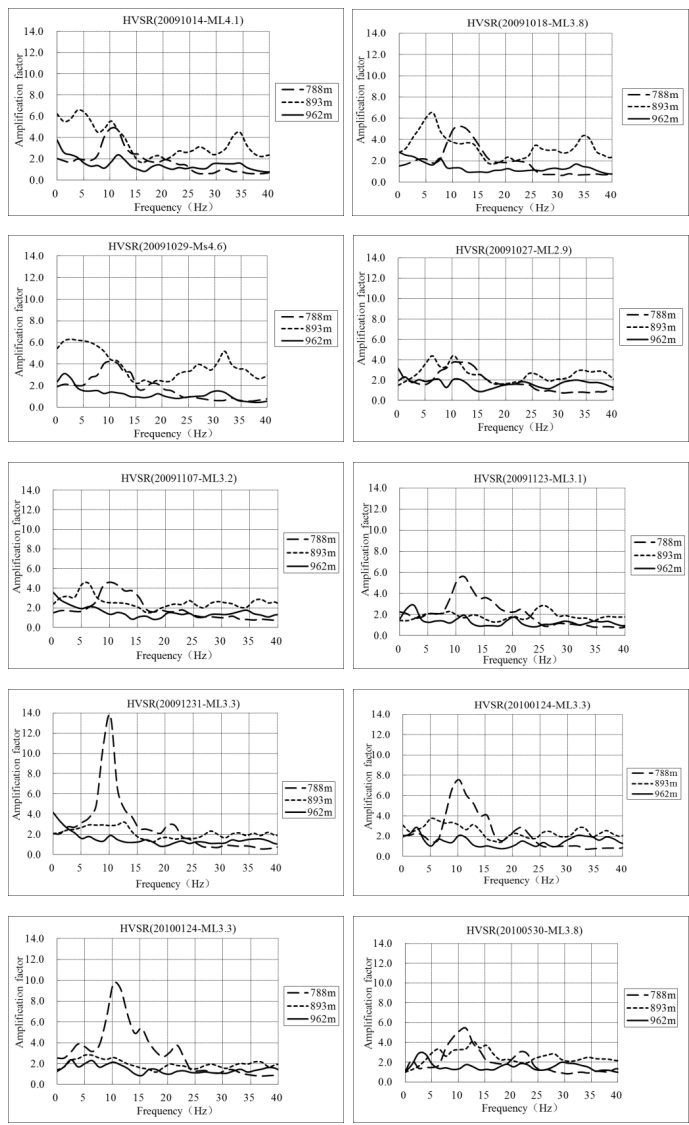

\section{NHESSD}

2, 4135-4161, 2014

The slope seismic response monitoring of Wenchuan

Y. H. Luo et al.

\begin{tabular}{|c|c|}
\hline \multicolumn{2}{|c|}{ Title Page } \\
\hline Abstract & Introduction \\
\hline Conclusions & References \\
\hline Tables & Figures \\
\hline I4 \\
\hline Back \\
\hline Full Screen / Esc \\
\hline Printer-friendly Version \\
\hline Interactive Discussion \\
\hline
\end{tabular}

Figure 12. Horizontal to vertical spectral ratio (HVSR) of typical aftershocks comparison at Mt. Shizi: $788 \mathrm{~m}$ equal to Q3 station, $893 \mathrm{~m}$ equal to Q8 station, $962 \mathrm{~m}$ equal to $\mathrm{Q} 9$ station.

Interactive Discussion 